\title{
PROPRIEDADE ANTIOXIDANTE DE COMPOSTOS FENÓLICOS: IMPORTÂNCIA NA DIETA E NA CONSERVAÇÃO DE ALIMENTOS
}

Marina Teixeira ACHKAR ${ }^{1}$; Gabriela Machado NOVAES ${ }^{1}$; Marcelo José Dias SILVA²; Wagner VILEGAS

\author{
Ciências Biológicas - Universidade Estadual Paulista Júlio de Mesquita Filho (UNESP) - Campus do Litoral Paulista; \\ marina_ta2@hotmail.com; gabriela.mnovaes@gmail.com \\ ${ }^{2}$ Doutorando em Ciências Farmacêuticas - Universidade Estadual Paulista Júlio de Mesquita Filho (UNESP) - Campus \\ do Litoral Paulista; marcelo_farma05@yahoo.com.br \\ ${ }^{3}$ Professor Titular em Química Orgânica - Universidade Estadual Paulista Júlio de Mesquita Filho (UNESP) - Campus \\ do Litoral Paulista - vilegasw@gmail.com
}

\section{Recebido em: 30/10/2013 - Aprovado em: 20/12/2013 - Disponibilizado em: 15/01/2014}

RESUMO: Os organismos vivos estão constantemente sujeitos a sofrerem ação de radicais livres, que são um dos causadores das reações de oxidação, pois possuem um elétron livre o que as torna muito reativos. Eles são produtos de reações do próprio organismo ou são produzidos por fatores exógenos, como tabaco. Os ácidos graxos são os alvos mais vulneráveis desse tipo de reação, podendo sofrer a peroxidação lipídica, o que afeta a estrutura das células. Doenças cardiovasculares, câncer e doenças do envelhecimento estão relacionados com a ocorrência dessas reações nos organismos. Os alimentos também estão sujeitos a sofrerem reações de oxidação, tornando-os impróprios para o consumo e diminuindo a vida útil. Compostos antioxidantes sintéticos são utilizados como conservantes de alimentos, porém apresentam certo grau de toxidade para o organismo. Estudos para a utilização de compostos antioxidantes naturais tem ganhado importância nas ultimas décadas, devido ao potencial de conservação e à baixa toxidade ao organismo. Compostos fenólicos estão amplamente distribuídos pelo reino vegetal e possuem alto potencial antioxidante devido à capacidade de neutralizar e sequestrar radicais livres. Esses compostos são utilizados pela indústria na conservação de alimentos, principalmente os ácidos fenólicos. O cosumo de alimentos ricos em compostos fenólicos, como chás, vinhos e frutos foi relacionado com a baixa incidência de doenças degenerativas. Este estudo consiste em uma revisão bibliográfica que abrange a importância desses compostos na dieta e na conservação de alimentos, e as metodologias e dificuldades no processo de extração devido a grande variedade de moléculas desse grupo.

Palavras-chave: Radicais Livres. Oxidação. Doenças Degenerativas. Antioxidante. Compostos Fenólicos.

\begin{abstract}
Living organisms are constantly subjected to the action of free radicals, which are one of the causes of oxidation reactions, because they have on free electron, what makes it very reactive. They are products of organism reactions or they are produced by exogenous factors, such as tobacco. Fatty acids are the most vulnerable target, and may suffer lipid peroxidation, what affects the cell structure. Cardiovascular diseases, cancer and diseases of aging are occurrence of these reactions in the organism related. The aliments are also subjected to suffer oxidation reactions, what make them unfit for consumption and decreasing the useful life. Synthetics antioxidants are used as aliments preservatives, but they present some toxicity for the organism. Studies for the utilization of natural antioxidants have gained more importance in recent decades, due to the conservation potential and low toxicity. Phenolics compounds are largely present at the vegetable kingdom and they present high antioxidant potential due to the neutralization and kidnapping of free radicals capacity. These compounds are used by the industry at the aliments conservation, specially the phenolics acids. The consumption of aliments rich in phenolic compounds, such as teas, wines and fruits are low incidence of degenerative diseases related. This study consists in a bibliographic revision that covers these compounds importance in diet and at the food conservation, and the methodologies and difficulties in the extraction process due to variety of molecules of this group.
\end{abstract}

Keywords: Free Radicals. Oxidation. Degenerative Diseases. Antioxidant. Phenolics Compounds. 


\section{Radicais livres e a Oxidação}

Os seres vivos estão a todo tempo sujeitos a sofrerem a ação de radicais livres. A ação dos radicais livres geram reações de oxidação, e diversos estudos mostraram que essas reações estão ligadas a doenças como câncer, aterosclerose, diabetes, artrite, malária, AIDS, doenças cardiovasculares e doenças do envelhecimento (DEGÁSPARI $e t$. al., 2004) Os radicais livres são um dos causadores das reações de oxidação em sistemas biológicos, pois possuem um elétron livre que pode se ligar a outro elétron de outro átomo, o que confere a alta reatividade desses elementos e o que provoca a reação de oxidação. Eles são produzidos pelos próprios processos biológicos dos organismos, ou por fatores exógenos, como o tabagismo, poluição do ar, solventes orgânicos, radiação, anestésicos e pesticidas. Nos sistemas biológicos, os ácidos graxos polinsaturados das membranas são muito vulneráveis ao ataque de radicais livres. Quando sofrem a oxidação, esses ácidos graxos passam por uma reação chamada peroxidação lipídica que afeta a estrutura e a funcionalidade da membrana celular, alterando a sua fluidez e sua permeabilidade. Ainda nos sistemas biológicos, as proteínas são afetadas pelos radicais livres, podendo sofrer fragmentação, cross linking, agregação e ativação ou inativação de enzimas, devido à reação dos aminoácidos constituintes das proteínas com os radicais livres. Os ácidos nucleicos também são afetados pelos radicais livres, podendo gerar alterações nas moléculas de DNA que resultam em aberrações cromossômicas, entre outros problemas genéticos (SOARES, 2002).

Espécies reativas de oxigênio (EROs) abstraem um hidrogênio das cadeias de ácido graxos polinsaturados dos fosfolipídios e do colesterol, dando inicio ao processo da peroxidação lipídica. Os radicais formados, quando reagem com o oxigênio, dão origem a radicais peroxila, que podem dar continuidade ao processo de oxidação, provocando sua propagação por outras moléculas de ácido graxo. Os radicais formados pela peroxidação lipídica formam compostos de vida curta que reagem com metais e causam danos ao DNA (SOUSA et. al., 2007).

Os alimentos também estão sujeitos a sofrerem reações de oxidação. Essas reações podem resultar na alteração do seu valor nutricional, e nos seus padrões de qualidade, como o odor, a cor, o sabor e a textura. A oxidação dos alimentos se deve a oxidação sofrida pelos lipídios que ocorre durante o processamento, a distribuição, o armazenamento e o preparo dos alimentos. Essas reações geram odores e sabores indesejáveis, o que torna os alimentos 
impróprios para o consumo. As reações também provocam as alterações nutricionais que afetam a integridade e a segurança dos alimentos, porque ocorre a produção de compostos potencialmente tóxicos (SOARES, 2002). A oxidação dos lipídios ocorre especificamente em ácidos graxos, encontrados na constituição dos glicerídeos. Essas alterações ocorridas nos alimentos são levadas em conta na determinação do tempo de validade dos produtos industrializados. Em alimentos com baixa atividade de água, a ação catalítica de metais é favorecida, o que propicia reações de oxidação de lipídios (DEGÁSPARI et. al., 2004)

\section{Atividade Antioxidante}

As reações de oxidação podem ser evitadas dependendo das condições ambientais ou através da utilização de compostos antioxidantes (SOARES, 2002). Os antioxidantes são substancias que impedem a formação de radicais livres ou impedem a etapa de propagação dessas reações doando hidrogênio de forma que a molécula alvo fique estável e assim agem no retardo ou na prevenção da oxidação (SOARES, 2002; BROINIZI et. al., 2007). A ingestão de alimentos que possuem substâncias antioxidantes ajuda a prevenir a oxidação proveniente dos processos biológicos, ou seja, de fatores endógenos ao organismo (DEGÁSPARI et. al., 2004). Antes da década de 80, antioxidantes sintéticos eram amplamente utilizados na prevenção da oxidação sofrida em alimentos industrializados, porém, a partir dessa década, iniciaram-se estudos destinados a produção de antioxidantes de fontes naturais, uma vez que foi detectado que antioxidantes sintéticos causam efeitos negativos e deletérios nos organismo quando utilizados em doses elevadas (BROINIZI et. al., 2007).

\section{Compostos Fenólicos}

Os vegetais são uma grande fonte de fitoquímicos que apresentam significante atividade antioxidante. Dentre esses fitoquímicos estão os compostos fenólicos como os carotenoides, o ácidos ascórbicos e tocoferóis (BROINIZI et. al., 2007). Os compostos fenólicos são muito utilizados na indústria de alimentos pela sua eficácia na prevenção da oxidação lipídica (SOARES, 2002). O consumo de alimentos ricos em compostos fenólicos possui relação com baixa incidência e baixa mortalidade por câncer (BROINIZI et. al., 2007). A utilização de compostos fenólicos, mais especificamente de ácidos fenólicos, como antioxidantes na conservação de alimentos pode aumentar a vida útil do produto entre 15 a $200 \%$ (SOARES, 2002). Os compostos fenólicos tem recebido grande atenção nos últimos anos por serem capazes de inibirem a peroxidação lipídica (SOUSA et. al., 2007).

A atividade antioxidante dos compostos fenólicos se deve ao seu papel na 
neutralização ou sequestro de radicais livres e na quelação de metais, agindo na etapa de iniciação e na etapa de propagação da peroxidação lipídica. Isso se deve a estrutura química e a capacidade redutora. Os produtos da ação antioxidante dos compostos fenólicos são relativamente estáveis devido à ressonância do anel aromático existente na estrutura (SOUSA et. al., 2007). Os compostos fenólicos apresentam grupos benzênicos que possuem pelo menos um de seus hidrogênios substituídos por um grupamento hidroxila (SOARES et. al., 2008).

Os compostos fenólicos podem ser classificados entre flavonoides e não flavonoides. Os incluídos no grupo dos flavonoides são as catequinas, epicatequinas, epigalocatequinas, caempferol, quercertina, miricetina, antocianincas, rutina $\mathrm{e}$ naringenina. Os incluídos no grupo dos não flavonoides são os ácidos fenólicos, ácido hidroxibenzóico , ácido hidrocinâmino e o resveratrol (ABE et. al., 2007 \& BIANCHI et. $a l ., 1999)$. Os flavonoides mais estudados são a quercetina, a rutina, a miricetina e a naringenina (BIANCHI et. al., 1999).

\section{Presença dos Compostos Fenólicos na Dieta}

$\mathrm{Na}$ alimentação, existem constituintes que possuem alta capacidade antioxidante. Os chás, por exemplo, estão presentes em abundancia na dieta da população mundial.
São elementos da alimentação ricos em catequinas, que é um dos seis tipos de flavonoides existentes. Pesquisas no Japão evidenciaram que o consumo de cinco ou mais xícaras de chá por dia estão inversamente relacionadas com a ocorrência das fases I e II do câncer de mama. Os chás feitos a partir do método de infusão, que é o despejo de água fervente sobre a erva, auxiliam na extração dos compostos fenólicos. Pesquisas feitas com chá de manjericão mostraram relação positiva entre a atividade antioxidante do chá e o teor de compostos fenólicos totais. Um estudo realizou a quantificação de fenóis totais de chás que são conhecidos popularmente e cosumidos pela população a fim de relacionar com suas características antioxidante e antibacteriana. A quantificação foi feita pela metodologia Folin-Ciocalteau, que é a metodologia mais utilizada na quantificação desses compostos. Os chás utilizados nessa pesquisa foram tanchagem, erva-mate, arruda, alecrim, macela, alcachofra, sálcia, camomila, capim-limão e malva. Os chás de erva-mate, tanchagem e alecrim mostraram maior teor de fenóis totais em seus extratos aquosos do que em seus extratos etanólicos, sendo que a ervamate foi o chá que mais apresentou compostos fenólicos. Quando se determinou a atividade antioxidante dos chás, a grande maioria mostrou essa atividade acima de $80 \%$ nos extratos etanólicos e nos aquosos, sendo que o da erva-mate apresentou atividade de 
95\% no extrato etanólico e acima de $97 \%$ no extrato aquoso (ASOLINI et. al., 2006).

Os sucos de uva também são conhecidos pela presença abundante de compostos fenólicos em sua composição. As uvas tintas possuem grande quantidade de flavonoides, principalmente de antocianinas, que são flavonoides responsáveis pela coloração azul violeta e tonalidades de vermelho de flores e frutos. As uvas brancas apresentam cinco vezes menos compostos fenólicos quando comparada com uvas tintas. As catequinas também estão presentes nas uvas e são responsáveis pela adstringência e pelo sabor dos vinhos e sucos, estando presentes em maior quantidade nas sementes. Os outros flavonoides, como a quercertina, caempferol e miricetina estão presentes nas uvas e tem grande influencia na coloração dos vinhos, atuando como co-pigmentos. Nas uvas encontramos componentes fenólicos não flavonoides como os ácidos fenólicos, que também vão influencias no sabor e aroma dos vinhos (ABE et. al., 2007).

O consumo de vinhos tem sido associado com a baixa incidência de doenças cardiovasculares. Estudos iniciaram-se a partir da observação da dieta francesa, que é rica em gorduras de origem animal, porém há baixa incidência de doenças cardiovasculares, apesar do consumo desse tipo de alimento agravar o risco de apresentar essas doenças. Esse fenômeno ficou conhecido como Paradoxo Francês (ABE et. al., 2007).
A presença de compostos fenólicos nas uvas se deve ao acumulo de açúcar que ocorre durante o processo de maduração das bagas. Esse fenômeno deriva na produção de álcool, polifenois, antocianinas, e outros compostos relacionados ao aroma. A composição das antocianinas nas uvas, tendo em vista que elas podem ser de diversos tipos, como a cianidina, a peonidina, a delfinidina, a petunidina e a malvidina, essa ultima presente em maior quantidade, depende de fatores genéticos, fatores climáticos e das características físico-químicas do solo. O teor de antocianinas teve relação com a capacidade antioxidante dos vinhos, sendo o composto que apresenta maior atividade antioxidante em relação aos outros compostos presentes na uva. Os outros compostos da uva também apresentam importância. Apesar da atividade antioxidante ser mais baixa, as catequinas e epicatequinas, por exemplo, inibem a proliferação celular. (ABE et. al., 2007)

Os compostos fenólicos mais estudados são o ácido gálico, o ácido elágico e o ácido caféico. O ácido elágico é encontrado nas uvas, nozes e morango e tem apresentado efeito preventivo no desenvolvimento de câncer causado pelas substancias do cigarro. Em relação aos flavonoides, a quercetina apresenta atividade antioxidante, apesar de poder reagir com o ferro e tornar-se um pró-oxidante. A miricetina, quercetina e rutina apresentaramse mais eficazes do que a vitamina $C$ na 
inibição de processos oxidativos induzidos pelo peróxido de hidrogênio no DNA. Epicatequeinas e rutinas apresentaram-se mais eficientes na atividade antioxidante de grupamentos hidroxila do que o manitol, que é um composto conhecido pela sua eficácia em sequestrar radicais hidroxilas. Outros flavonoides presentes em chá verde e chá preto são inibidores do processo de carcinogênese (BIANCHI et. al., 1999).

Frutas tropicais apresentam alto valor nutritivo e efeitos terapêuticos, e devido a isso seu consumo tem aumentado de ano em ano. Além de seus nutrientes, como fibras e minerais, as frutas tropicais apresentam compostos fenólicos como compostos secundários. Um estudo determinou o teor de fenóis totais de frutas tropicais amplamente consumidas. Entre as estudadas, amoras e uvas apresentaram maior teor de antocianinas, enquanto que acerola e goiaba apresentaram o menor. Extratos de baguaçu também apresentaram altos teores de antocianinas. O mesmo estudo determinou a atividade antioxidante dos extratos das frutas estudadas e o resultado apresentou relação positiva entre o teor antocianina e da atividade antioxidante. Os frutos que não contem antocianina também apresentaram atividade antioxidante devido à presença de vitamina $\mathrm{C}$, mas essa mesma vitamina apresentou menor influencia na atividade do que os compostos fenólicos. $\mathrm{O}$ estudo mostrou que mesmo poupa de frutas congeladas, produto amplamente comercializado, mantiveram as suas propriedades e ainda assim sendo excelentes fontes de antioxidantes (KUSKOSKI et. al., 2006).

As maçãs também são alimentos ricos em compostos fenólicos, sendo que nelas esses compostos estão presentes no vacúolo das células, em maior quantidade nas células da epiderme e subepiderme quando comparada a quantidade desses compostos do tecido interno da fruta (NOGUEIRA et. al., 2003). O consumo de maçãs apresentou o melhor resultado relacionado com a prevenção de tumores no pulmão comparado com o consumo de outras fontes de flavonoides em um estudo realizado por Knekt et. al. (BIANCHI et. al., 1999) No processamento para a produção do suco de mação, os compostos fenólicos podem ser perdidos, devido à ação da enzima polifenoloxidase, causadora do escurecimento, e também à formação de precipitados. Nesse caso, é necessária a utilização de compostos antioxidantes sintéticos para evitar a oxidação causada no processamento do suco devido a perda dos compostos fenólicos (NOGUEIRA et. al., 2003).

Plantas do gênero Acacia são conhecidas pela propriedade antioxidante. Quatro espécies desse gênero tiveram sua atividade relacionada com a presença de polifenóis, como os flavonoides e taninos. O mel obtido a partir de plantas desse gênero 
apresentou alto potencial antioxidante e elevado teor de compostos fenólicos (ANDRADE et. al., 2007).

O consumo de compostos fenólicos presentes em uma dieta rica em vegetais que apresentam esses compostos pode auxiliar na ação de medicamentos farmacêuticos potencializando seus efeitos. Esses compostos não são conhecidos como nutrientes, pois ainda não foram relatados estados de deficiência para compostos fenólicos. Além disso, esses compostos podem se ligar a receptores celulares e transportadores de membrana, influenciando na expressão gênica. Dessa forma, os compostos fenólicos possuem outras funções importantes no organismo vivo, além da atividade antioxidante (GIADA et. al., 2006).

\section{Metodologia de Extração: Cuidados e Dificuldades}

Existem inúmeros tipos de antioxidantes provenientes de fontes naturais, e não existem métodos de extração específicos para nenhum dos tipos. As características dos diversos compostos fenólicos existentes vão exigir a utilização de solventes de polaridades diferentes para a extração e isolamento de cada composto. Alguns compostos fenólicos possuem alto peso molecular e são insolúveis em água, por isso deve-se conhecer a estrutura do composto fenólico que se deseja isolar e escolher um solvente que seja de polaridade adequada para a extração desse composto. Em uma pesquisa realizada com folhas de Blumea balsamífera, utilizou-se éter, clorofórmio e metanol para a extração de 11 tipos de flavonoides diferentes, o que possibilitou a analise e a determinação da atividade antioxidante desses flavonoides. O extrato metanólico apresentou maior atividade antioxidante em relação aos outros extratos. Em outra pesquisa realizada com cacau, o extrato metanólico também foi o que melhor apresentou extração de componentes antioxidantes. Em geral, solventes com polaridades mais baixas apresentam melhor extração de compostos antioxidantes do que misturas contendo metanol ou etanol (ANDREO et. al., 2006).

Um estudo realizado com casca de laranja obteve uma fração na qual se utilizou acetato de etila e que pode ser utilizada como antioxidante em alimentos e na formulação de medicamentos, devido ao seu alto teor de compostos fenólicos e propriedade sequestradora de radicais livres (ANDREO et. al., 2006).

O tempo de extração influencia significantemente a obtenção de polifenois, podendo variar de 1 minuto a 24 horas. Se o tempo de extração se prolongar, será necessária a adição de agentes redutores ao solvente utilizado devido a possível oxidação sofrida pelos polifenois. Uma pesquisa realizou extração de frutas vermelhas em metanol, etanol e água, em tempos de 1, 12 e 24 horas para cada solvente. Evidenciou-se 
que na extração feita com água, o teor de compostos fenólicos diminuiu com o passar do tempo, enquanto que nos outros solventes ocorreu o aumento do teor de compostos fenólicos com o passar do tempo (ANDREO et. al., 2006).

O próprio processo de extração causa diminuição do teor de compostos fenólicos através da secagem, que provoca degradação química e enzimática, e através da volatilização dos compostos. A decomposição térmica tem sido apontada como a principal causa da redução do teor desses compostos, pois nesse processo, os fenóis podem reagir com outros compostos, o que impede a extração dos mesmos. O teor de compostos fenólicos diminui de acordo com o aumento da temperatura (ANDREO et. al., 2006).

\section{Conclusão}

Os compostos fenólicos estão amplamente distribuídos no reino vegetal, e por isso são facilmente encontrados em componentes da dieta. Isso é um ponto positivo, uma vez que o consumo desses alimentos proporciona vantagens à saúde do organismo devido às propriedades antioxidantes, prevenindo doenças degenerativas que possuem alta ocorrência na população. Os estudos para a obtenção desses compostos para a conservação de alimento devem continuar, pois a utilização de antioxidantes sintéticos pode causar sérios danos ao organismo, e os compostos fenólicos são encontrados com grande facilidade na natureza. Um grande problema nos estudos desses compostos é a metodologia a ser utilizada para a extração. Esse grupo é composto por diversos subgrupos, que possuem características distintas entre si e cada subgrupo com grande quantidade de moléculas existentes. Com isso, se tem moléculas de diferentes tamanhos e polaridades, que vão exibir comportamentos diferentes e vão necessitar de metodologias distintas para cada tipo. Por isso, o ideal é conhecer o tipo de composto fenólico presente na amostra estudada, para a utilização de uma metodologia eficaz para aquele determinado tipo de composto fenólico. Porém, nem sempre se conhece o composto presente na amostra. Isso tem se tornado um grande desafio no estudo desses compostos.

\section{REFERÊNCIAS}

ABE et. al.; Compostos Fenólicos e Capacidade Antioxidante de Cultivares de Uvas Vitis labrusca L. e Vitis vinifera L. Ciênc. Tecnol. Aliment., Campinas, 27(2): 394-400, abr.-jun. 2007

ANDRADE et. al.; Determinação do Conteúdo Fenólico e Avaliação da Atividade Antioxidante de Acacia podalyriifolia A. Cunn. Ex. G. Don, Leguminosae-mimosoideae. Revista Brasileira de Farmacognosia 17(2): 231-235, Abr./Jun. 2007

ANDREO et. al.; Antioxidantes Naturais: Técnicas de Extração. - B.CEPPA, Curitiba v. 24, n. 2, p. 319-336, jul./dez. 2006 
ANSOLINI et. al.; Atividade Antioxidante e Antibacteriana dos Compostos Fenólicos dos Extratos de Plantas Usadas como Chás. . J. Food Technol., v.9, n.3, p. 209-215, jul./set. 2006

BIANCHI et. al.; Radicais Livres e os Principais Antioxidantes da Dieta. Rev. Nutr., Campinas, 12(2): 123-130, maio/ago., 1999

BROINIZI et. al.; Avaliação da Atividade Antioxidante dos Compostos Fenólicos Naturalmente Presentes em Subprodutos do Pseudofruto de Caju (Anacardium occidentale L.). Ciênc. Tecnol. Aliment., Campinas, 27(4): 902-908, out.-dez. 2007

DEGÁSPARI et. al.; Propriedades Antioxidantes de Compostos Fenólicos. Visão Acadêmica, Curitiba, v. 5, n. 1, p. 3340, Jan.- Jun./2004

GIADA et. al.; Importância dos Compostos Fenólicos da Dieta na Promoção da Saúde Humana. Publ. UEPG Ci. Biol. Saúde, Ponta Grossa, 12 (4): 7-15, dez. 2006
KUSKOSKI et. al.; Frutos Tropicais Silvestres e Polpas de Frutas Congeladas: Atividade antioxidante, polifenóis e antocianinas. Ciência Rural, v.36, n.4, julago, 2006.

NOGUEIRA et. al.; Efeito do Processamento no Teor de Compostos Fenólicos em Suco de Maçã. Publ. UEPG Ci. Exatas Terra, Ci. Agr. Eng., Ponta Grossa, 9 (3): 7-14, dez. 2003

SOARES; Ácidos Fenólicos como Antioxidantes. Revista de Nutrição, 15(1):71-81, jan./abr., 2002

SOARES et. al.; Compostos Fenólicos e Atividade Antioxidante da Casca de Uvas Niágara e Isabel. Rev. Bras. Frutic., Jaboticabal - SP, v. 30, n. 1, p. 059-064, Março 2008

SOUSA et. al.; Fenóis Totais e Atividade Antioxidante de Cinco Plantas Medicinais. Quim. Nova, Vol. 30, No. 2, 351-355, 2007 